\title{
CONF-961178--1 Battery Testing For Photovoltaic Applications
}

\author{
Tom Hund
}

\author{
Photovoltaic System Applications Department, \\ Sandia National Laboratories, Albuquerque, NM 87185-0753
}

\begin{abstract}
Battery testing for photovoltaic (PV) applications is funded at Sandia under the Department of Energy's (DOE) Photovoltaic Balance of Systems (BOS) Program. The goal of the PV BOS program is to improve PV system component design, operation, reliability, and to reduce overall life-cycle costs. The Sandia battery testing program consists of: 1) PV battery and charge controller market survey, 2) battery performance and life-cycle testing, 3) PV charge controller development, and 4) system field testing. Test results from this work have identified market size and trends, PV battery test procedures, application guidelines, and needed hardware improvements.
\end{abstract}

REEUED

NOV 29 1996

OSTI

\section{INTRODUCTION}

The Photovoltaic (PV) battery testing work at Sandia is funded by the Department of Energy's (DOE) Photovoltaic Balance of Systems (BOS) Program. Additional funding for the PV battery market survey has been provided by Sandia's Battery Analysis \& Evaluation Department funded by the DOE Office of Utility Technology. In addition to work conducted at Sandia, the Florida Solar Energy Center (FSEC) is also funded by Sandia to conduct PV battery cycle-life testing and field evaluations. The goal of this work is to improve PV system component design, operation, and reliability to reduce overall PV system life-cycle costs. This work includes:

1) conducting a market survey of PV batteries and charge controllers to evaluate the market size, use patterns, and direction of growth in the PV industry (Arizona State University),

2) conducting PV battery performance and cycle-life testing to identify specific battery charging characteristics that are important to improving battery cyclelife in PV systems (Sandia and FSEC),

3) working with PV charge controller manufacturers to improve component design, performance, and reliability (Sandia), and

4) conducting PV system field tests to verify and quantify potential performance improvements resulting from improved charge controllers and charging strategies (Sandia and FSEC). 


\section{PV Battery Charging}

Batteries in PV systems are subject to degrading use environments that may be unique to PV systems. These degrading environments stem from four sources: 1) PV systems only have a limited amount of time and energy to recharge the battery, 2) inadequate battery maintenance, 3) improper system design, and 4) improper battery design. This report looks at battery charging issues only.

Battery recharge is subject to solar resource that can be well below normal for weeks at a time. PV system battery recharge methodology is known in the battery industry as "opportunity charging". "Opportunity charging" differs greatly from traditional battery applications such as motive power deep-cycle, starting lighting and ignition (SLI), or uninterruptible power supply (UPS) float applications in that when the battery is under charge it may only receive a partial incomplete charge for long periods of time. This partial charge condition causes electrolyte stratification and/or irreversible sulfation in flooded deep-cycle lead-antimony batteries. After months in a partial charge condition, full recovery generally requires more charge than most PV/charge controller systems are capable of providing. ${ }^{1}$ The degree to which premature PV battery capacity loss occurs in PV systems with flooded batteries is dependent on system design, regulation voltage, and battery design. Even well designed PV systems experience some premature battery capacity loss because of the lower PV regulation voltages and the lack of battery equalization. ${ }^{2}$

In addition to the problems associated with flooded batteries, the new gel or absorbed glass mat (AGM) valve regulated lead-acid (VRLA) batteries have additional PV battery charging difficulties. This is due primarily to the fact that VRLA batteries require a more precise charge control algorithm which varies depending on the manufacturer and type of VRLA battery. Several other problems immediately occur because of the use of on/off PV charge controllers with low reconnect voltages $(\sim 13.4$ volts). These on/off charge controllers can be very inefficient because they terminate charging prematurely. VRLA batteries are much more sensitive to regulation voltage (typical 14.1 to 14.4 volts at $25^{\circ} \mathrm{C}$ ) and require much more time at regulation voltage than flooded batteries. They are also much less tolerant of excess charge. VRLA battery manufacturers recommend constant voltage charging for their batteries, but most PV systems use on/off charge control. ${ }^{6}$ The result is under- or over-charged batteries. The biggest problem with on/off charge controllers is identifying the correct set-points that provide the best cyclelife for a particular PV system design. If the VRLA battery is being charged at an excessively high voltage, then it will vent excess gas and lose capacity from loss of electrolyte or battery dry-out. ${ }^{3}$ Permanent capacity loss can also occur from under charging resulting in irreversible sulfation. There is just a narrow window of 


\section{DISCLAMMER}

Portions of this document may be illegible in electronic image products. Images are produced from the best available original document. 
charging parameters that a VRLA battery will operate under and still achieve rated cycle-life.

\section{POTENTIAL COST SAVINGS}

Present PV systems using batteries for backup power add at least $\$ 0.10$ to $\$ 0.50$ per $\mathrm{kWh}$ to the system life-cycle cost for battery backup (assuming 100\% charge efficiency and full rated life of the battery). ${ }^{4,5}$ These battery cost values vary due to the quality and type of battery used (golf cart vs. industrial VRLA). If true battery charging efficiencies are factored ( 70 to $90 \%)$ and battery life is cut in half, then battery costs can easily exceed $\$ 0.26$ to $\$ 1.30$ per $\mathrm{kWh}$ over the life of the system. This simple calculation indicates that battery costs can be equal to or greater than the life-cycle costs of the PV modules (assuming PV life-cycle costs of $\$ 0.25$ per $\mathrm{kWh}$ or $\sim \$ 6 / \mathrm{Wp}$ ). Therefore, the potential cost benefit to stand-alone PV systems is substantial if batteries meet their rated life expectancy.

\section{PV BATTERY AND CHARGE CONTROLLER SURVEY}

This survey was funded by the DOE Office of Utility Technology through Sandia's Battery Analysis and Evaluation Department in support of the Photovoltaic System Applications Department. The survey was conducted by Bob Hammond of Arizona State University to better define the market size, hardware, operating environments, and future growth trends. Survey participants included:

1) 8 large PV system integrators,

2) 13 small PV system integrators,

3) 9 battery manufacturers, and

4) 8 charge controller manufacturers.

In addition to the survey, all participants were asked what they felt Sandia could do to expand the market for PV batteries. The completed results will be published by Sandia in December of $1996 .{ }^{6}$

Table 1 presents a preview from the battery survey listing total flooded and VRLA battery sales from the $21 \mathrm{PV}$ system integrators for 1995 . The data indicates that $64 \%$ of the PV batteries sold are VRLA with a dollar value of $\$ 3.4$ million. A topdown market analysis conducted by Bob Hammond using data from other sources and the survey also indicates that the total US PV battery market is about $\$ 33.8$ million, therefore the PV systems houses share of this market is about $14 \%$. The survey establishes that the majority of PV systems are using VRLA batteries. With 
this in mind, it is very important to better understand the charging requirements of these batteries in PV systems.

Table 1. Total PV Battery Market For Surveyed System Integrators

\begin{tabular}{|l|cc|cc|cc|c|}
\hline \multirow{2}{*}{ Battery Technology } & \multicolumn{7}{|c|}{ 1995 } \\
\cline { 2 - 9 } & \# of Units & $\%$ of \# & (Wholesale) & $\%$ of \$ & kWhr & $\%$ of kWhr & \$/kWhr \\
\hline \hline Valve Regulated & 16,846 & 64 & $3,421,455$ & 71 & 26,632 & 57 & 113 \\
Flooded Vented & 9,462 & 36 & $1,387,720$ & 29 & 20,012 & 43 & 75 \\
\hline Total & 26,308 & 100 & $4,809,175$ & 100 & 46,644 & 100 & 94 \\
\hline
\end{tabular}

Included in the survey was a question directed to the PV charge controller manufacturers and system integrators requesting input on what Sandia could do to expand the PV battery market. The most predominant response was to provide assistance in the characterization of batteries for PV systems. Fifty-four percent of the small system integrators and $71 \%$ of the large system integrators indicated that this was their highest priority for support from Sandia.

\section{PV BATTERY LIFE-CYCLE TESTING}

Battery manufacturers over the years have directed their design efforts toward 1) automotive starting, lighting, and ignition (SLI) batteries, 2) uninterruptible power supply (UPS) batteries, and 3) deep-cycle motive power batteries. All of these applications have very specific design requirements that may not be appropriate for PV systems. Much of the SLI and motive power battery performance data is obtained using Battery Council International (BCI) test procedures. ${ }^{7}$ The BCI test procedures include specific tests for:

1) vehicular starting, lighting, and ignition (SLI) batteries,

2) electric vehicular and cycling batteries,

3) cycle-life testing of golf cart batteries,

4) cycle-life testing of deep cycle marine/RV batteries, and

5) cycle-life testing of floor maintenance batteries.

None of the above tests are specific to PV systems and the data that is generated is not directly applicable to PV systems. Controlled PV battery tests are not possible in fielded PV systems because of variations in solar resource, therefore, the use of an automated battery tester was purchased from Firing Circuits to conduct PV battery testing at Sandia. The indoor test data can be used as a basis to modify system design, justify improved charge controllers, and evaluate new battery charging strategies. Improvements in PV battery performance will require a comprehensive approach that includes laboratory testing, improved system designs, improved battery application notes, improved charge controllers, and field 
verification. This is the approach taken at Sandia's PV System Applications Department.

\section{Test Procedure Development}

Test results from previous indoor testing, using a 10\% depth of discharge (DOD) shallow cycle, identified several important points that need to be considered in any PV battery test procedure. ${ }^{8,9}$ The test procedure considerations are:

1) Battery recharge is highly dependent on regulation voltage, charge/discharge rate, and time at regulation voltage/available energy.

2) Battery charge acceptance degrades in shallow cycling up to about 25 cycles.

3) Battery regulation voltage is dependent on battery temperature.

An example of the effect of charge rate on charge acceptance is in Figure 1. Figure 1 shows a GNB VRLA battery's overcharge (Ah charged - Ah load/Ah load x 100) as a function of the charge/discharge rate and the number of consecutive shallow cycles. The DOD and available Ah for recharge were the same for all test cases. As seen in Figure 1, the percentage overcharge with this test procedure is much higher ( 20 to $40 \%$ ) for a 10 -hour recharge and 8-hour discharge than for a 5 -hour recharge and 2-hour discharge (5 to $12 \%$ ). GNB recommends 5 to $10 \%$ overcharge for this 12-5000X VRLA battery. Also shown in Figure 1 is the effect of shallow cycling, which decreased overcharge or charge acceptance after each consecutive cycle. Significant variations in battery charge acceptance will occur in PV systems because of changes in charge rate, array sizing (array to load ratio), and temperature.

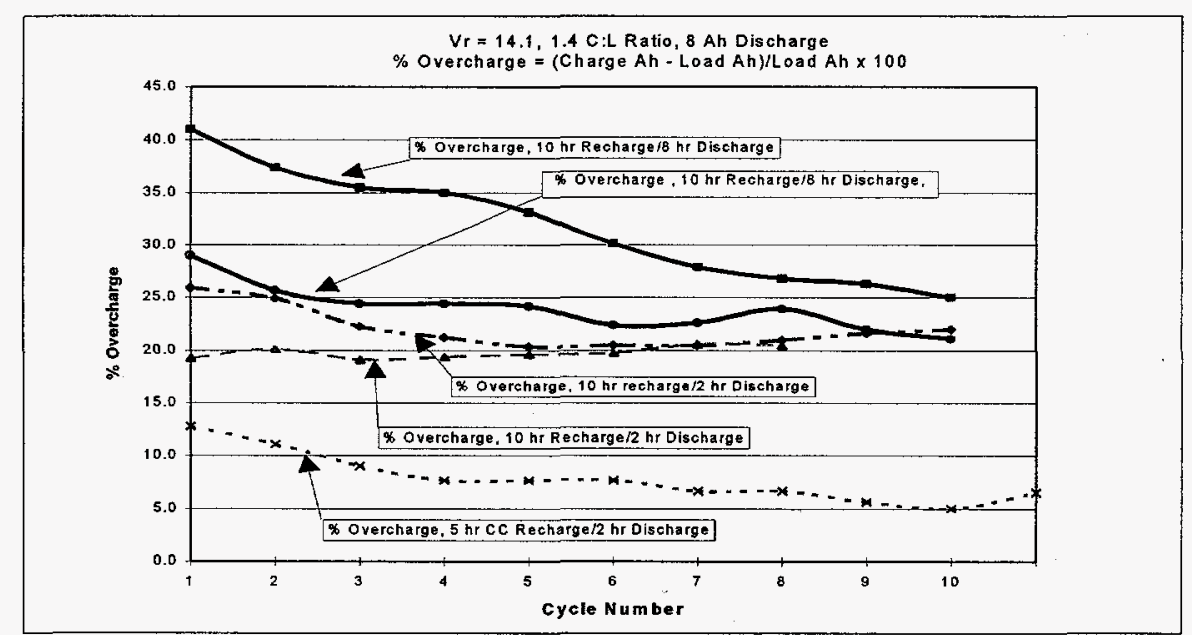

Figure 1. GNB 12-5000X Battery \% Overcharge (Charge Acceptance) As Function of Charge/Discharge Rate And Cycle Number 
In order to optimize battery performance in PV systems the effects of regulation voltage (Vr) set-points, charge/discharge rates, and array to load ratios must be well understood. It is also not known how the interaction of the above PV system parameters affect battery cycle-life. Higher battery cycle-life in PV systems is the end objective of the Sandia PV battery testing.

The most effective way to identify the effects and interactions of the Vr set-point, charge/discharge rate, and array to load ratio on battery cycle-life is the use of an experimental design and statistical analysis technique called Design of Experiments. ${ }^{10}$ This technique will improve the quality of data, minimize testing, and identify the interactive relationships between the variables. In this case, the Design of Experiments procedure centers around a statistical analysis software package called MINITAB $^{\circledR}$ that identifies the experimental design and processes the test results. The experimental model used for this evaluation is called the Central Composite Design and requires 20 test cases for three variables. MINITAB ${ }^{\circledR}$ is capable of designing the test plan and processing the cycle-life performance results to provide statistical diagnostics, main effects plots, and performance contour plots of all variables. This experimental technique is now being used at FSEC to provide a comprehensive cycle-life performance map of the GNB 12-5000X AGM VRLA battery which is very similar to the GNB Absolyte IIP battery. Both batteries are commonly used in PV systems.

\section{Test Procedure}

1) Initial Battery Charge - Returns lost battery capacity from self discharge during storage after manufacturing.

2) Initial Capacity Test - Measures initial battery capacity at the test rate for one cycle. Abort voltages will be extracted from this test. The manufacturers recommended recharge procedure will be used. This test verifies battery capacity and health.

3) Cycle-Life Tests - Cycles batteries in a scenario that resembles the daily charge/discharge cycles of a PV system. (See Table 2 for test points and Figure 2 for example test sequence).

a) 25-shallow cycles at specified variables. Cycle-life testing will be terminated when the battery is unable to deliver $80 \%$ of the Initial Capacity measured by end of load voltage (EODV).

b) 4-deficit charge cycles discharging $60 \%$ of initial capacity. Abort test when the battery EODV indicates that $80 \%$ of its capacity has been discharged.

c) 2-deficit charge cycles to 11.4 volts.

d) Recovery charge cycles based on charge to load (C:L) ratio or regulation voltage. Recovery cycles will be calculated based on (Ah DOD/charge - 
discharge $A$ h) +5 cycles.

e) Sustaining shallow cycles using the specified variables in step (a). Cyclelife testing will be terminated when the battery is unable to deliver $80 \%$ of the Initial Capacity measured by EODV. The total number of cycles per test sequence will be 91 . (Temperature is not varied in these tests, and all tests are to be performed at a nominal $25^{\circ} \mathrm{C}+1-3^{\circ} \mathrm{C}$ ambient temperature. Stabilized temperature baths or room temperature control are required.)

4) Data Processing - Cycle-life results are input into MINITAB $^{\circledR}$ from the 20 battery cycle-life test points for data processing.

The experimental design requires the identification of a low and a high value for regulation voltage, charge rate, and C:L ratio. The Design of Experiments software will identify the other points required for the Central Composite Design (see Table 2).

Table 2. Test Points For The 80 Ah GNB 12-5000X AGM VRLA Battery Test At FSEC

\begin{tabular}{|l|c|c|c|c|c|}
\hline & \multicolumn{3}{c|}{ Test Points } & \multicolumn{2}{c|}{ Axial Test Points } \\
\hline \multicolumn{1}{|c|}{ Variable } & High & Low & Center & High & Low \\
\hline Voltage Set-Point & 14.4 & 13.8 & 14.1 & 14.6 & 13.6 \\
\hline Charge/Discharge Rate (amps) & 4 & 1.6 & 2.3 & 8.2 & 1.3 \\
\hline Charge to Load Ratio (Based On Time) & 1.5 & 1.1 & 1.3 & 1.64 & 0.96 \\
\hline Temperature (Deg. C) & 25 & 25 & 25 & 25 & 25 \\
\hline Depth of Discharge (\%) & 20 & 20 & 20 & 20 & 20 \\
\hline
\end{tabular}

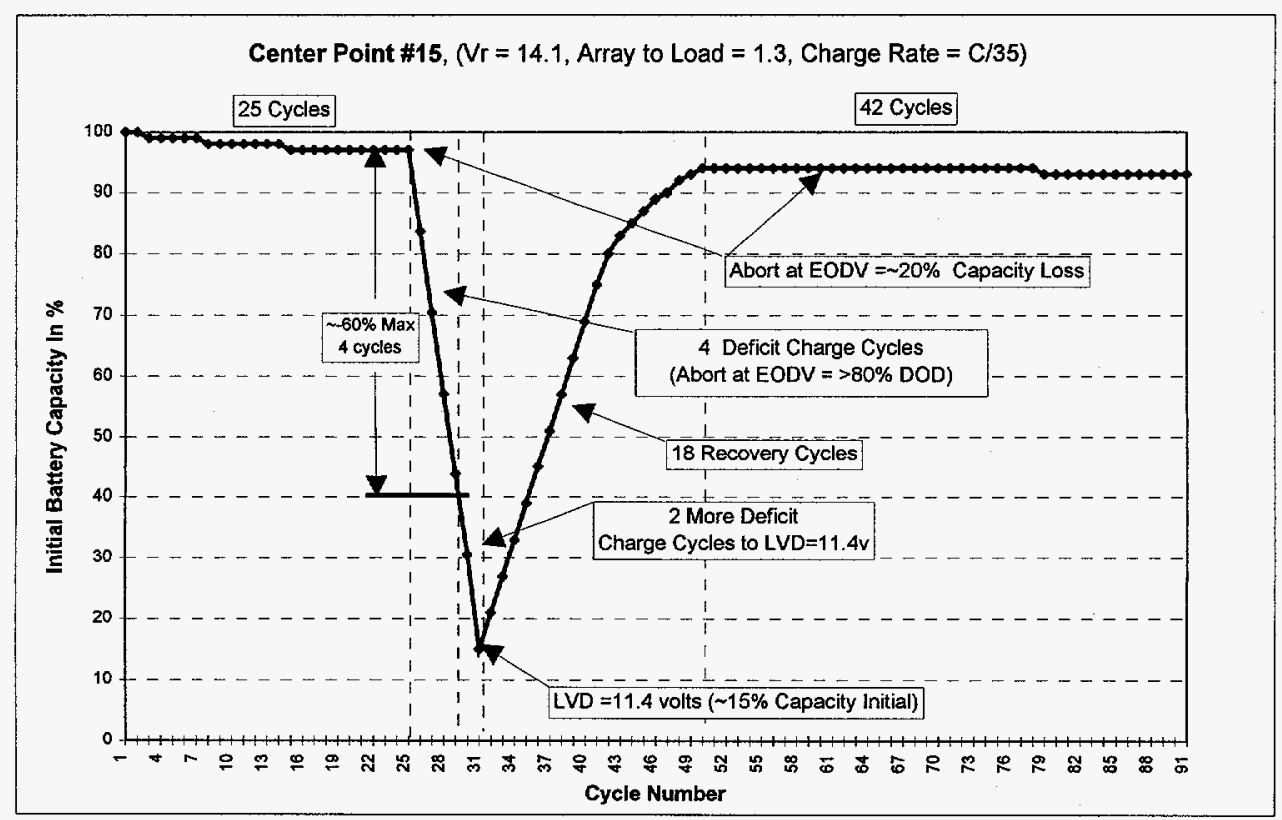

Figure 2. Simulated Example: PV Battery Cycle-Life Test Sequence 


\section{Experimental Design/Data Reporting Format}

The Central Composite Design provides a higher quality prediction over the region of interest where main, interaction, and curvature effects are needed. All three of the above effects are used by MINITAB $^{\circledR}$ to define the individual variable responses ( $\mathrm{Vr}$, rate, $\mathrm{C}: \mathrm{L}$ ), and identify the regression equations and coefficients necessary to map the response curvature which illustrates how factors influence the performance response (cycle-life). For this experimental design, MINITAB $^{\oplus}$ has defined 20 tests for the given variables in Table 1 . There are 8 tests to measure the response variable (Cycle-Life) at the corner (high and low) points, 6 tests to measure the response variable at the axial points (points on the axis outside the base cube), and 6 tests to measure the response variable at the center point. The high and low values are defined by the experimenter and MINITAB ${ }^{\circledR}$ calculates the other levels. The completed test sequence provides MINITAB $^{\circledR}$ with all of the performance responses that are required to obtain the Residual Model Diagnostics (Figure 3 ), Main Effects Plot (Figure 4), and Performance Contour Plots (Figure 5 ). Three contour plots are required to fully map the interactions of the variables to the performance parameter (Cycle-Life).

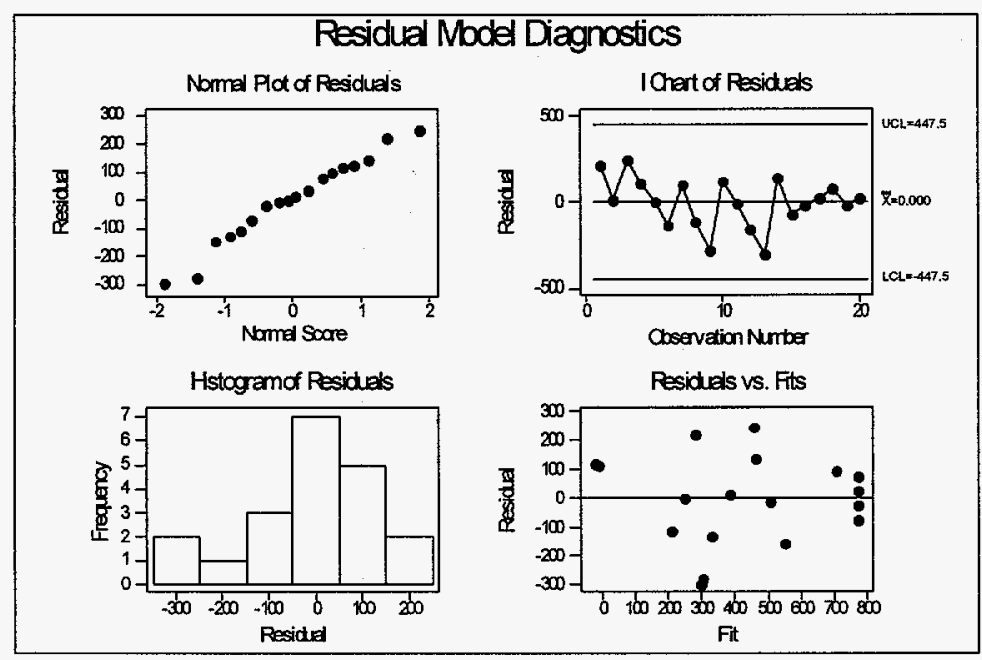

Figure 3. Simulated Residual Model Diagnostics 


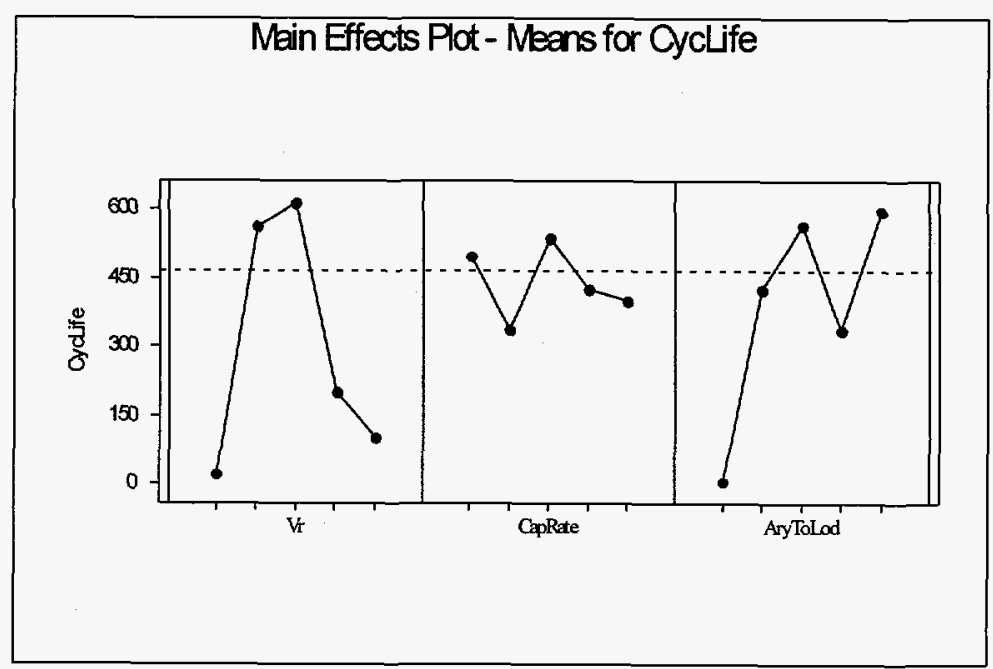

Figure 4. Simulated Main Effects Plot

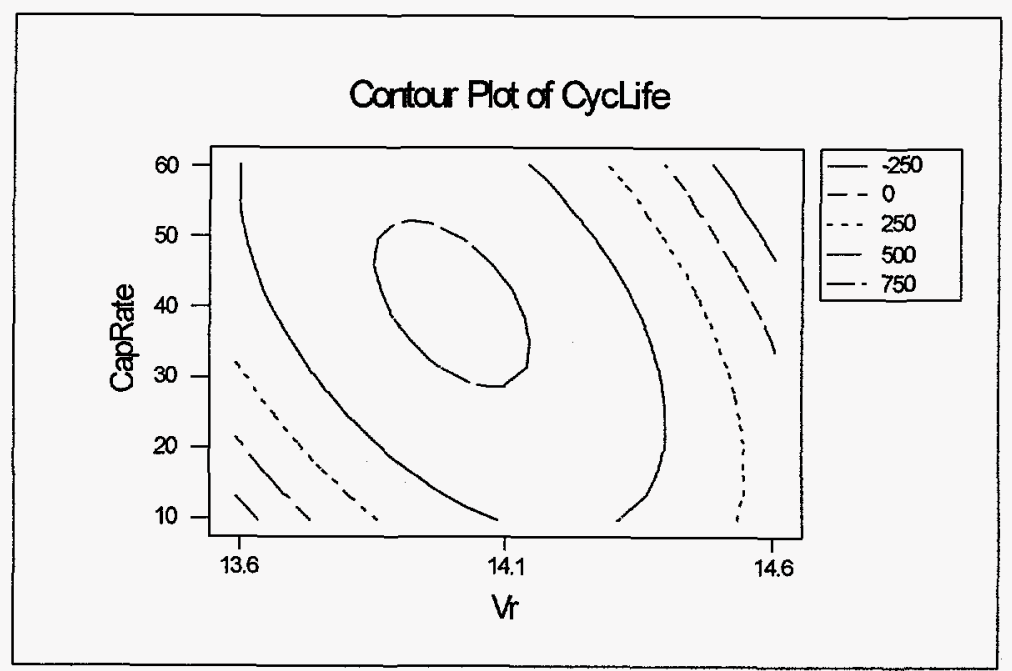

Figure 5. Simulated Contour Plot Of Cycle-Life (CycLife) Vs. Regulation Voltage (Vr) and Charge/Discharge Rate (CapRate)

\section{PV Battery Cycle-Life Test Results}

Figure 6 and 7 show the preliminary battery overcharges and end of discharge voltages from test case \#1 and \#15. This test sequence is only being conducted using constant voltage charge control. At a later time the pulse width modulated charge control algorithm will be tested using a PV charge controller. In Figure 6, test case \#1 (corner point), the battery is not recharging all of the deficit Ah. This is clearly indicated by the fact that in the first three cycles, the recharge $\mathrm{Ah}$ are between 97 to $100 \%$ and the EODV is dropping from 12.30 to 12.12 volts. It is interesting to note that after the first three cycles, the battery begins to receive a slight excess in recharge $\mathrm{Ah}(+2 \%)$. This is an indication of an initial capacity loss 
and improved charge acceptance at the lower battery capacity. The battery reached the abort criteria soon after this chart was prepared (-20\% Capacity Loss).

In Figure 7, test case \#15 (center point), the battery recharge $\mathrm{Ah}$ which are between 107 and $112 \%$ of the discharge Ah show that the battery is receiving about $8 \%$ overcharge after the initial 25 cycles. This is within the manufacturers specified 5 to $10 \%$ overcharge which indicates that the battery should see a much improved cycle-life over test case \#1. Until this test is concluded it is difficult to say how long the battery will cycle. The test data here only indicates that this battery is being recharged within the recommended limits.

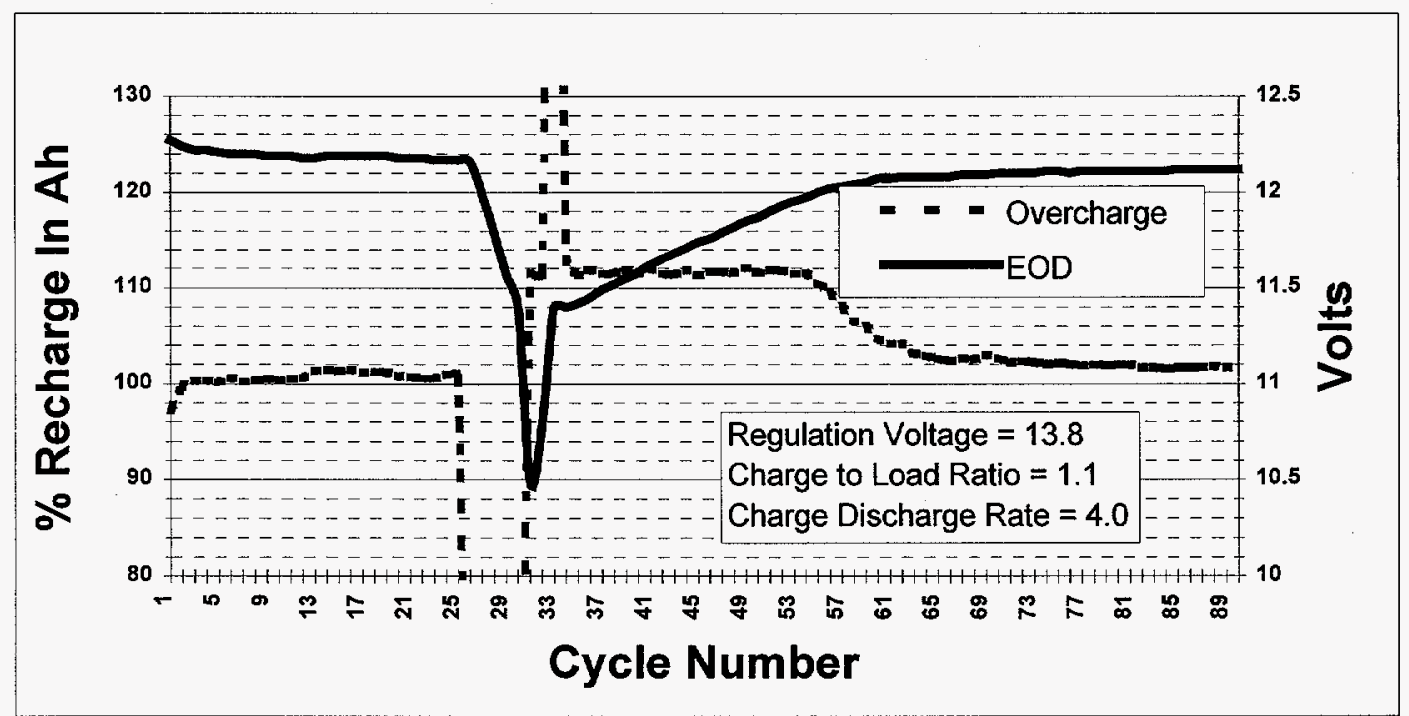

Figure 6. Test Case \#1, Corner Point, PV Cycle-Life Test

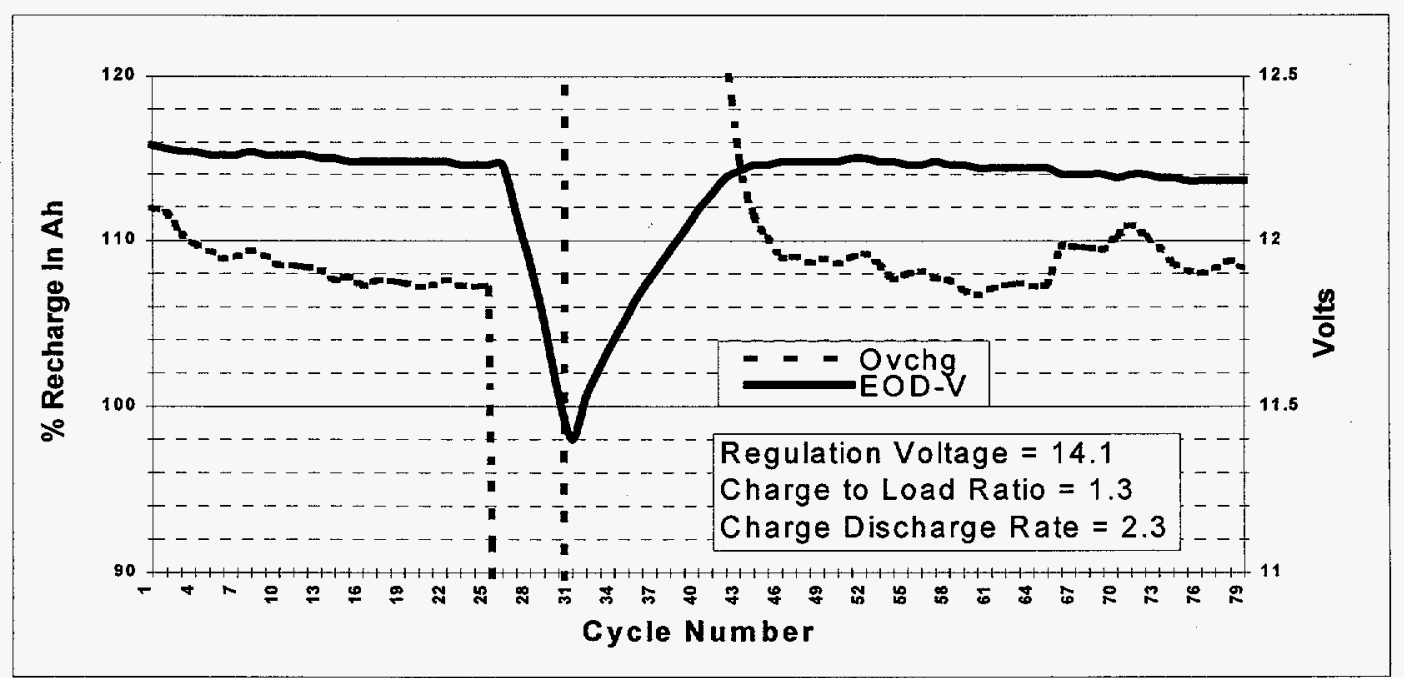

Figure 7. Test Case \#15, Center Point, PV Cycle-Life Test 


\section{PV CHARGE CONTROLLER AND FIELD TESTING}

Sandia is now working with Morningstar and Digital Solar Technologies to test lower cost, improved performance, and higher reliability charge controllers such as the SunSaver PWM charge controller and the MPR-9400 microprocessor based PV charge controller. Some examples of this work are identified below.

\section{Morningstar SunSaver}

The development of this charge controller was partially funded by Sandia as part of DOE's Photovoltaic BOS Program. The SunSaver has been in field tests for over six months. The SunSaver has demonstrated exceptional performance and reliability for a small ( $<10 \mathrm{amps})$ low cost PV charge controller. It increases charge acceptance in VRLA batteries which should improve VRLA battery cycle-life. The increased charge acceptance is due to the PWM charge algorithm. Previous work ${ }^{11}$ has indicated that improved charge acceptance is possible "...by discharging prior to charging or during the charging process". Figure 8 is an example of the SunSaver providing the battery with charge and discharge current pulses. This may be responsible for the improved charge acceptance seen when used with VRLA batteries. Field tests have shown that the SunSaver does provide VRLA batteries with a much higher overcharge or charge acceptance.

Figure 9 is an example of how the PV Battery Cycle-Life Test can be used to evaluate battery charge acceptance. In this test the Morningstar SunSaver was placed in series with the Firing Circuits automated battery cycle tester to make a direct comparison between DC constant voltage charging and PWM charging using the same VRLA battery and test program for both charge algorithms. This battery after being cycled for over 200 cycles using the constant voltage charge algorithm and the indicated set-points, "permanently" lost over $20 \%$ of its capacity; down from 99 to $73 \mathrm{Ah}$. The battery capacity could not be recovered with constant voltage charging. SunSaver test results now indicate that much of the battery capacity has been recovered. This is indicated by the deficit charge cycle which removed $74 \mathrm{Ah}$ at 11.46 volts. Previous capacity tests on this battery resulted in about $10 \mathrm{Ah}$ of battery capacity between 11.5 and 10.5 volts. This indicates that an increase in battery capacity of about 11 Ah has occurred from the SunSaver PWM PV charge controller. 


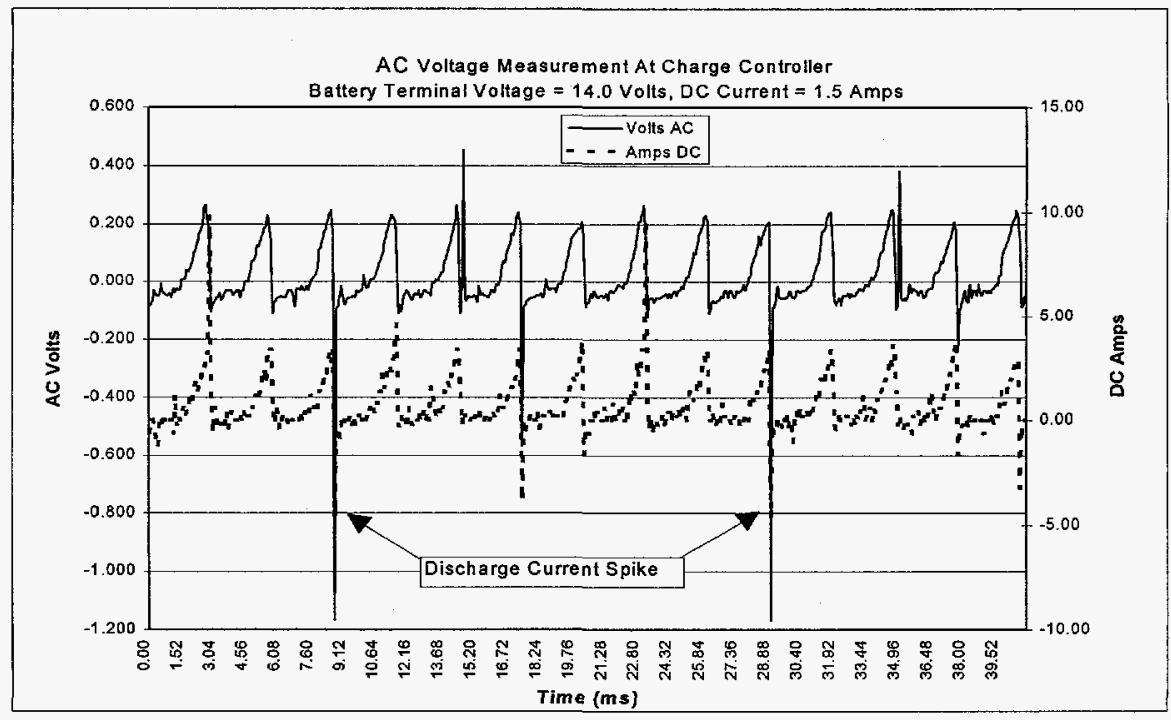

Figure 8. SunSaver Pulse Width Modulated Charging Showing Charge and Discharge Current Spikes

The test results in Figure 9 also indicate that the Morningstar SunSaver is providing the GNB 12-5000X AGM VRLA battery with 2 to $8 \%$ more overcharge compared to the constant voltage charge algorithm. In addition to the increased overcharge, the PWM charge controller is charging at 14.0 volts instead of 14.1 volts due to a voltage drop from the internal electrical resistance in the battery tester. The SunSaver is also charging the battery at about $25^{\circ} \mathrm{C}$ compared to the constant voltage data at about $27^{\circ} \mathrm{C}$.

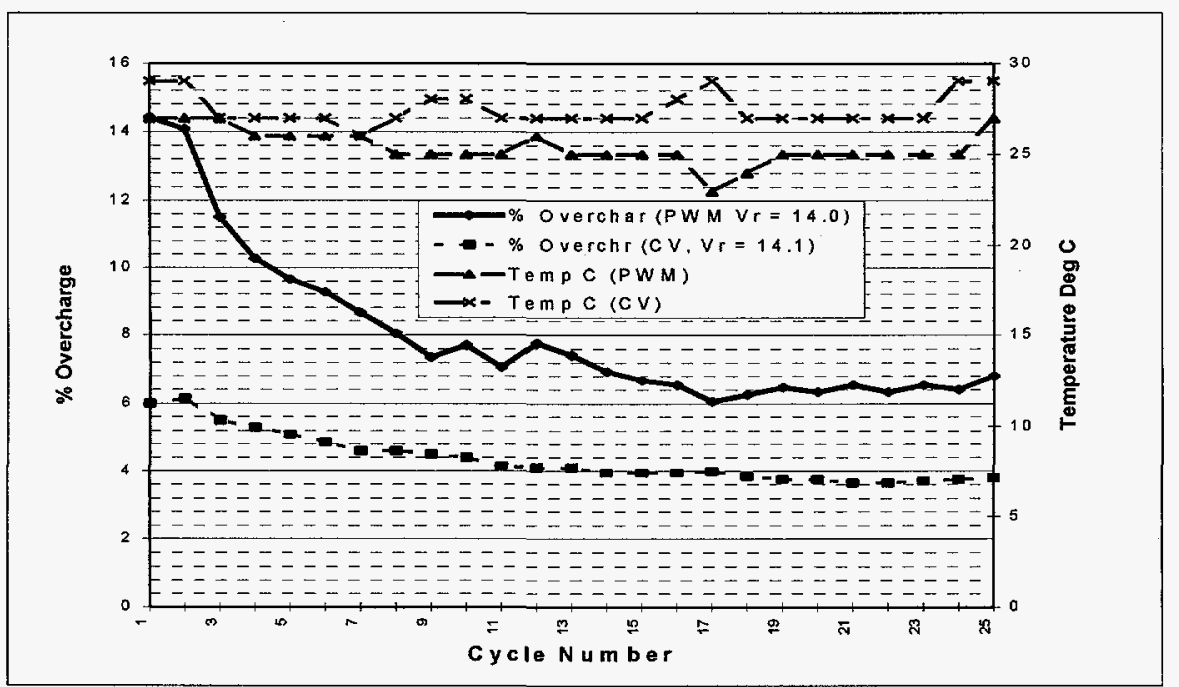

Figure 9. PV Battery Cycle-Life Test Comparing Constant Voltage Charging vs. Pulse Width Modulated Charging Using A GNB 12-5000X VRLA Battery 
Both of these factors will reduce the overcharge for the PWM charger. In addition to the laboratory tests, field test results have shown that the SunSaver provides a much higher overcharge $(>25 \%)$. The above test results certainly indicate that the PWM charger will charge the battery more efficiently with a lower voltage. Tests are continuing to evaluate the effect PWM and overcharge will have on battery cycle-life.

\section{Digital Solar Technologies MPR-9400}

A new amp-hour (Ah) counting PV charge control algorithm developed in a cooperative effort with Digital Solar Technologies and implemented in their MPR-9400 microprocessor based PV charge controller is presently under test at Sandia. Previous Sandia analysis of PV hybrid power systems indicated that traditional voltage regulated charge control was not the most effectively way to charge batteries for hybrid power systems with multiple power sources and complex loads. Battery management in complex hybrid systems is difficult because of daily and seasonal load or DOD changes and fluctuations in solar resource. The new Digital Solar Technologies MPR-9400 Ah counting charge control algorithm and automatic battery equalization function have already demonstrated in preliminary testing that flooded deep-cycle batteries can be charged in a more effective way in hybrid power systems. Work is presently underway to demonstrate this new charge algorithm for the GNB VRLA battery technology.

The new Ah counting charge control algorithm requires the user to input several parameters into the MPR-9400. These parameters include:

1) HVD-1 \& 2 Battery regulation voltage (Input by user)

2) AHDOD Maximum depth of discharge per cycle (Counted by MPR9400)

3) \%OVER Maximum overcharge above AHDOD (Input by user)

4) \%ADD Deficit or excess battery Ah at initial battery regulation voltage (Input by user)

5) AHVRESET Battery voltage when new cycle or HVD's are reactivated (Input by user)

6) BATAHINIT Battery capacity (Input by user)

7) BatAH Maximum battery Ah recharged per cycle (Counted by MPR-9400)

Figure 10 shows the first test results for a GNB 12-5000X AGM VRLA battery bank. The Ah counting charge control disables the high voltage disconnect (HVD) 
1 and 2 when the specified overcharge in Ah is reached (BatAH). The charge control algorithm requires the input of the battery capacity (BATAHINIT) which is $250 \mathrm{Ah}$, the preset maximum overcharge (\%OVER) which is $5 \%$, a battery Ah adjustment for regulation voltage (\%ADD) which is $5 \%(12.5 \mathrm{Ah})$, and the cycle reset voltage (AHVRESET) which is 12.5 volts. The maximum recharge in Ah per cycle (BatAH) is dependent on the daily depth of discharge (AHDOD), \%ADD, and \%OVER input values and are calculated using the Campbell data logger to be between 253 and $254.5 \mathrm{Ah}$. This resulted in a battery overcharge of 7.9 to $12 \%$, which is within the battery manufacturer's recommended values.

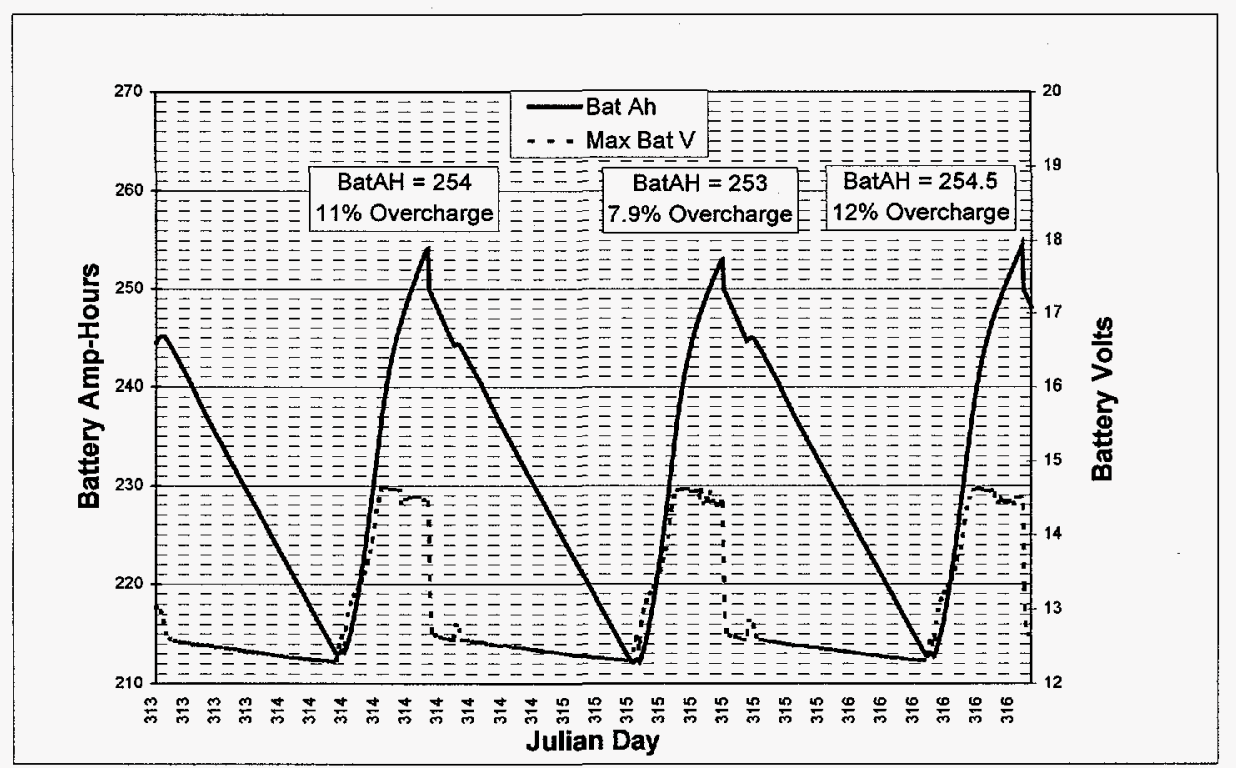

Figure 10. Ah Counting Charge Control on GNB 12-5000X VRLA Batteries. Battery Capacity Measured Using MPR-9400 Charge Control Algorithm. Battery Temperature is 13 to $15^{\circ} \mathrm{C}$.

When the Ah counting charge control algorithm has completed its initial performance testing on the GNB VRLA battery technology, it will be a significant advancement in PV hybrid charge control strategy. VRLA battery charge control will be greatly improved by providing the maximum available charge without under- or over-charging the batteries in variable resource or low load periods. This will extend cycle-life by reducing dry-out and maximizing state of charge.

\section{SUMMARY}

The Sandia PV battery testing program has already made significant steps toward its goal of improved PV battery cycle-life and lower life-cycle costs. This work has produced: 
1) a detailed PV battery market survey,

2) PV Battery Test Procedure,

3) SunSaver charge controller

4) improved charge algorithm for the MPR-9400, and

5) improved PV system battery charging using the new charge controllers.

Work is now continuing to complete the cycle-life testing at Sandia and FSEC and to confirm field performance improvements using the new PV charge controllers. The PV battery and charge controller survey, battery test results, and charge controller test results will be distributed to the industry to facilitate the use of more reliable PV hardware and improved system design.

\section{ACKNOWLEDGMENTS}

Without the work and support of Garth Corey from Sandia's Battery Analysis \& Evaluation Department, the battery survey would not have been done. This work was a significant and much appreciated addition to the PV battery testing program.

\section{REFERENCES}

1. Woodworth, J.R., Harrington, S.R., Dunlop, J.D., et al, "Evaluation of the Batteries and Charge Controllers in Small Stand-alone Photovoltaic Systems", First World Conference on Photovoltaic Energy Conversion, Hawaii, Dec. 1994.

2. Harrington S. R., Hund T. D., "Photovoltaic Lighting System Performance," $25^{\text {th }}$ IEEE Photovoltaic Specialists Conference, Washington, May 1996. Pp. 1307-1400.

3. Whitehead M. L., "Failure Mechanisms In VRLA Batteries," Proc. of $8^{\text {th }}$ Battery Conference and Exhibition, Solihull, UK, May 1994, pp. 2.1.1 - 2.1.10.

4. Strong S., The Solar Electric House, "Voltage Regulators, Battery Chargers, Storage Batteries," Solar Design Associates, Inc., (508) 456-6855.

5. University of Cape Town Energy for Development Research Centre, Remote Area Power Supply (RAPS) Design Manual, ISBN:0 7992 1435 3, Ph. (021) 650-3230, Sept. 1992.

6. Hammond R. L., Turpin J. F., Corey G., Hund T., and Harrington S. R., "Photovoltaic Battery \& Charge Controller Market \& Applications Survey - An Evaluation Of The Photovoltaic System Market For 1995," Sandia Contractor Report \# SAND96-xxxx, Dec. 1996.

7. Battery Council International, Battery Technical Manual $2^{\text {nd }}$ Edition, 401 North Michigan Av. Chicago, Illinois 60611, (312) 644-6610. 
8. Dunlop J., and Swamy R., "Evaluation of Batteries and Charge Controllers In Small Stand-Alone PV Systems," Florida Solar Energy Center, Contractor Reports, Nov. 1996.

9. S.R. Harrington, and T. D. Hund, "Rating Batteries for Initial Capacity, Charging Parameters and Cycle Life in the Photovoltaic Application", PCIM , Sept., 1995

10. Box G.E.P., Hunter W.G., and Hunter J.S., Statistics For Experimenters, Wiley, NY, 1978.

11. Joseph A. Mas, “The Charging Process," Proc. $2^{\text {nd }}$ Int. Electric Vehicle Symposium, Electric Vehicle Council, 1971, pp. 228-246. 